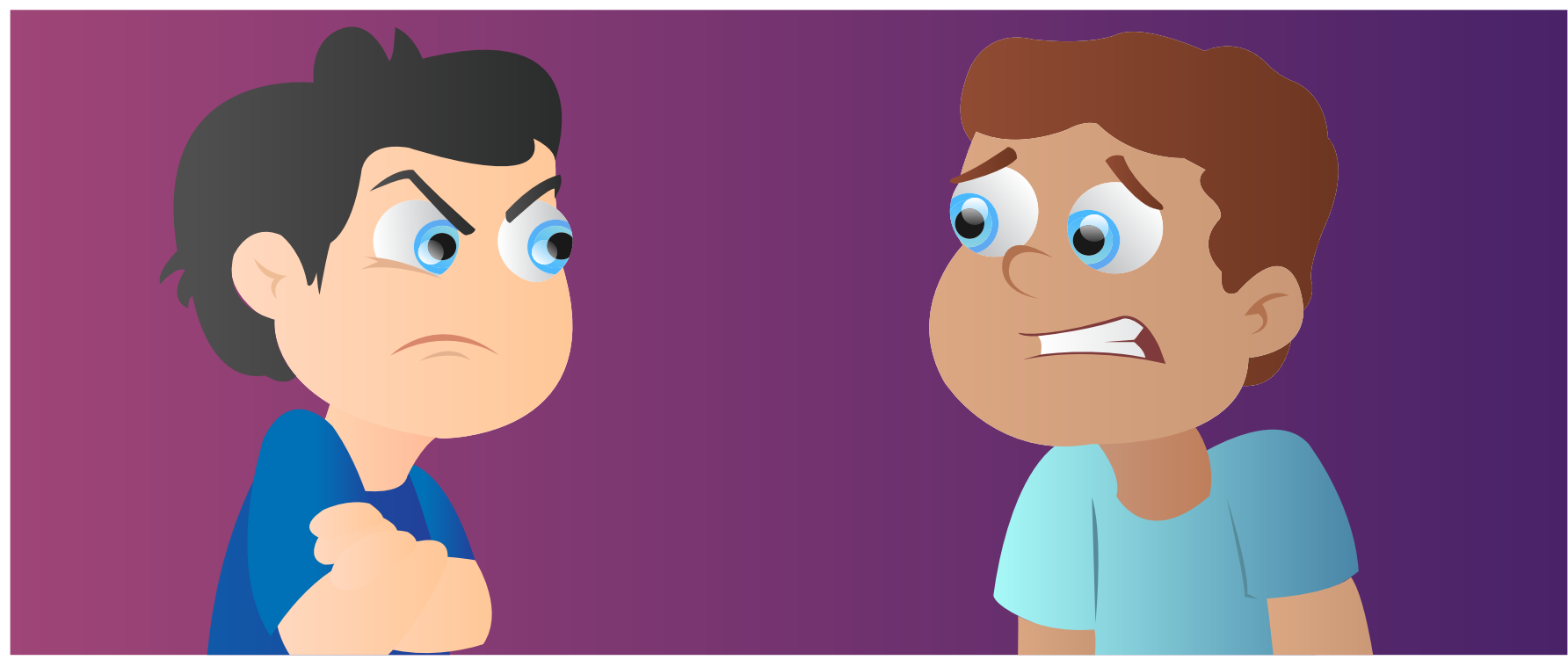

\title{
HOW WE READ EMOTIONS FROM FACES
}

\section{Marianna Pogosyan ${ }^{1}$ and Jan Benjamin Engelmann ${ }^{2 *}$}

${ }^{1}$ Graduate School of Arts and Sciences, International Christian University, Tokyo, Japan, ${ }^{2}$ Center for Research in Experimental Economics and Political Decision Making, Amsterdam School of Economics, University of Amsterdam and the Tinbergen Institute, Amsterdam, Netherlands

\section{REVIEWED BY:}

JENAPLANSCHOOL DE LANTEERNE 9-10 YEARS OLD
The ability to read emotions from faces is a very important skill. One might even call it a superpower. People around the world use this skill when they communicate with each other. But do people from different cultural backgrounds recognize and interpret facial expressions the same way? The answer, according to scientists, is both yes and no. Yes, because the brain system specializing in understanding faces is similar across cultures, so we all can recognize basic emotions, such as happiness or sadness, when looking at other faces. No, because culture influences how we behave and how we think, which means it also influences the rules we learn as children that tell us when and how to show our emotions. In this article, we discuss how we are able to read emotions from faces and how we might be reading emotions differently, depending on where we are from.

\section{INTRODUCTION}

Imagine if I told you that you could have a superpower that would allow you to know something very personal about other people-their feelings. With just one look at a special map, you would know if people are happy, sad, angry, or bored, without them telling you anything. Well, almost all of us have this 
FUSIFORM GYRUS

The fusiform gyrus is located at the bottom of the brain and stretches throughout almost $2 / 3$ of the length of the brain (starting in the occipital lobe shown in Figure $1 \mathrm{~A}$ and extending forward through the temporal lobe). It is involved in visual perception, such as understanding color Importantly, the fusiform face area is part of the fusiform gyrus, and this region is particularly important for understanding faces (and body parts).

\section{FUNCTIONAL} MAGNETIC RESONANCE IMAGING (FMRI)

A medical technique that allows scientists and medical professionals to make images of the brain with the help of strong magnetic fields. MRI scanners can take three-dimensional pictures of the structure of the brain and also measure the oxygen content of the blood that flows to the brain. The changes in the oxygen content of the blood reflect how active neurons are and can, therefore, be used to measure brain activity during functional MRI superpower already. And the map that we use every day to read other people's emotions is the face.

How can we tell what people are feeling from their facial gestures? Does this superpower work the same way everywhere in the world?

To understand the mechanism behind reading emotions, let us think about the human face. Have you ever heard the saying "The eyes are the windows to the soul"? Maybe it is a bit unlikely to see someone's soul through their eyes (our eyes are not real windows after all), but one of the reasons why people use this saying is because the eyes are very important for understanding what other people are feeling. In fact, we can learn a lot about others from their facial expressions, and other people can tell a lot about us from our faces. Think about all the ways you can express emotions using just your face! Even babies seem to be born understanding the importance of faces, because as early as 9 minutes after birth, babies prefer to look at faces rather than any other objects [1]. By the time they are 12 days old, babies can already imitate the facial gestures of adults [2]. This ability is very important for their development because it helps them to later learn how to speak and to think.

\section{THE ROLE OF THE BRAIN IN READING FACES}

But why is it important for us to be able to read emotions from other people's faces? The reason is that understanding others' emotions can be important for our survival and well-being. Imagine, for example, that on one sunny day, you and your friend are standing in a field and talking about your favorite game. You are laughing and chatting and enjoying your conversation. Suddenly, your friend's face turns from smiling to scared, and his eyes abruptly shift from looking at you to looking behind you. Now your friend has you really concerned. And you should be! You turn around and follow your friend's gaze and what do you see? A huge, hungry bear running toward you! In this case, your ability to read your friend's emotions from his facial gestures might save your life (superpowers can do that).

It is, therefore, no surprise that the brain is very much involved in interpreting information from others' faces. Scientists have discovered that large parts of the brain are responsible for understanding what we see. Regions of the brain that participate in this function are part of what is called the "visual system" and it is located largely at the back of the brain, in what is called the occipital lobe (red region in Figure 1A). Within the visual system, there is a special part that plays an important role in interpreting information revealed by faces, such as who someone is and how she feels. This area is called the fusiform face area, which is part of the fusiform gyrus (for short FFG, see Figure 1B). Using special equipment to take images that measure the amount of oxygen in the brain, called a functional magnetic resonance imaging scanner, scientists have shown that when people look at pictures of faces, the fusiform area of 


\section{FIGURE}

Important regions in the face perception network of the brain. This figure shows regions that are central to interpreting facial expressions of emotions. Panel A shows the occipital lobe (in red), which is an essential part of the brain system that interprets information that we take in with the eyes. In Panel B, you are looking at the brain as if a person that is a little smaller than you is looking straight at you. The figure shows the fusiform gyrus (in green), which is important for understanding who someone is and what they are feeling, and the amygdala (in green), which is important for understanding emotions. The amygdala is a smaller region located on both sides of the brain. The brain figures were created using Neurosynth, an online tool that combines information from many functional magnetic resonance imaging studies.

\section{AMYGDALA}

The amygdala is a region in the brain that is shaped like an almond. It can be found on both sides of the brain, about where a straight line drawn through the eyes meets with a straight line drawn through the ears. It is involved in a number of behaviors, including learning and memory, emotions, and detecting important events in the environment.

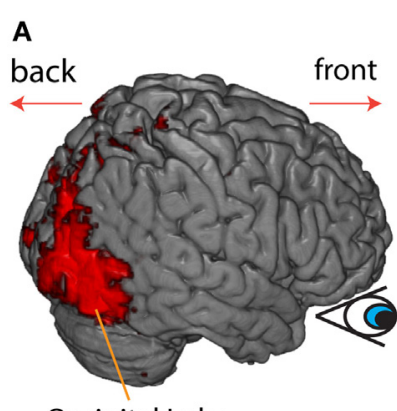

Occipital Lobe

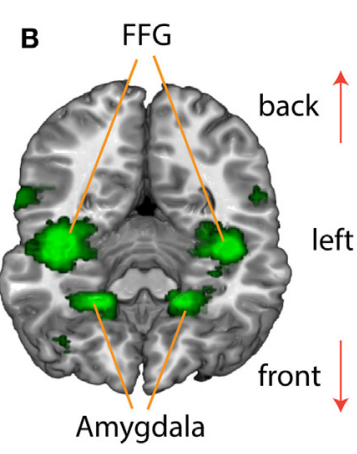

FIGURE the brain shows more activity, compared with when the same people look at pictures of nature or houses [3].

To understand emotions, the visual system works together with other parts of the brain. One of these parts is called the amygdala. The amygdala is very important for reading others' emotions. It is located in the lower part of the brain (Figure 1B). So, whenever you try to understand your friends' emotions, your amygdala and your FFG communicate with each other. When different areas of the brain frequently talk to each other, these areas form a network. The FFG and amygdala are part of the face perception network of the brain [4]. When parts of the face perception network are damaged, for instance because of an accident, then people will have difficulty recognizing others' faces and interpreting others' emotions [5]. Sometimes, they can even have trouble recognizing their own faces when they look in the mirror. This is a condition that is called prosopagnosia, which is also known as face blindness.

\section{HOW DOES CULTURE INFLUENCE THE WAY WE SHOW EMOTIONS?}

Human beings around the world have similar brain structure and use similar facial muscles to express basic emotions such as happiness, sadness, fear, surprise, anger, and disgust. Does this mean that we all express and read each other's emotions the same way? The answer, according to scientists who study emotions, is both yes and no. While many experiments have shown that people around the world can accurately recognize basic emotions, such as happiness, sadness, anger, and fear, other research has shown that there are differences in the way people read facial expressions depending on where they are from. This makes sense when we consider that people in different cultures do not all behave and think the same way.

One of these cultural differences is found in display rules. Display rules are rules that we learn as children that tell us how and when to express our emotions. For example, in some countries, like the US, display rules say that it is OK to show our emotions to others when we are very sad or very happy, and 


\section{DISPLAY RULES}

Rules about when, where, and how it is appropriate to express emotions. Usually, people learn these rules as they begin to socialize with others from their own culture. Scientists have shown that depending on the culture that people come from, there might be differences in display rules. it is polite to look into people's eyes while doing so. In other countries, like Japan, display rules say that it is better not to show too many strong emotions around other people, and that looking into people's eyes is considered impolite. Scientists have been studying display rules for many years and in many different cultures, in order to understand how they influence the way people around the world express and read emotions. Almost 50 years ago, a now famous experiment showed how display rules differ across cultures [6]. In this experiment, American and Japanese participants were asked to watch stressful videos two times. The first time, they watched the films alone, and the second time, they watched with another person (an experimenter) in the room. The experiment showed that both the Japanese and American participants had similar facial expressions when they watched the movies alone. But when there was someone else in the room with them, the Japanese participants preferred not to show their negative feelings. Instead, in order to hide their negative feelings, they began to smile. The Americans, on the other hand, continued to display their negative emotions in front of the experimenter. Scientists concluded that the reason why the Japanese and American participants acted differently in the presence of other people was because of the display rules they had learned in their cultures.

\section{PEOPLE FROM DIFFERENT CULTURES ANALYZE EMOTION EXPRESSIONS DIFFERENTLY}

Display rules not only tell us how and when to express emotions but also influence how we see and understand emotions in others. For example, in some cultures, people are used to seeing faces that show a lot of strong emotions. In others, where display rules say that emotions should not always be strongly expressed, people are used to faces with less expression. When you see emotional expressions of similar strength often enough in your own culture, this influences the way you read those emotions from facial expressions.

So, what if you want to figure out what someone is feeling. Which part of the face gives you your biggest clue? The answer to this question comes from experiments that used eye trackers. An eye tracker is a special device that monitors eye movements and, therefore, can tell scientists exactly where a person is looking. Eye trackers allow scientists to study what regions of the face people pay most attention to (for example, the eyes or the mouth) when they are trying to understand others' emotions. These experiments showed that depending on where people are from, they focus their attention on different parts of the face when trying to figure out what others are feeling. East Asian participants, for example, mostly look for clues from the eyes. Western participants find their clues more from the whole face, including the eyes, the eyebrows, the nose, and the mouth. This suggests that people from different cultures express their emotions using different facial signals, and also, different cultures analyze facial gestures differently [7]. One reason for these cultural differences is that display rules also influence the way we 
FIGURE 2

Emoticons commonly used in eastern and western cultures. This figure shows how emoticons commonly used in eastern cultures, such as Japan (left column) and western cultures, such as the United States (right column) differ. Emotions expressed by emoticons are listed in the middle column. Notice how the eastern emoticons express different emotions via the eye region, while western emoticons express emotions mostly with the mouth.

\begin{tabular}{ccc} 
Eastern & Emotion & Western \\
\hline$\left({ }^{\wedge}{ }^{\wedge}\right) /$ & Happy & $:-)$ \\
$\left(\lambda_{-}\right)$ & Angry & $=:-0$ \\
$\left\{\left\{\left(>_{-}<\right)\right\}\right.$ & Fearful & $:-($ \\
$\left({ }_{-}\right)$ & Sad & $:-0$ \\
$\left(\odot_{-} \odot\right)$ & Surprised & $: \$$ \\
$(\frown-\frown ;)$ & Embarrassed & \\
\hline
\end{tabular}

FIGURE 2

process information from the face and the way we categorize this information into emotions.

What if you saw a face where the eyes and the mouth are showing different emotions (for example, the eyes are sad, but the mouth is happy)? Would you pay more attention to what the eyes are displaying or what the mouth is displaying? One experiment showed that people will have different answers depending on their culture [8]. Japanese people mostly read the emotion signaled by the eyes, while Americans focused more on the mouth region to read the emotion. In fact, you can see a similar pattern when you look at emoticons (emojis) used in different cultures. Emoticons are symbols that use letters, punctuation marks, or numbers to express emotions. In Asia, for example, most emoticons use different eye shapes to express different emotions. In western cultures, most emoticons use different mouth shapes to express emotions (Figure 2).

\section{TRAINING AND TESTING YOUR SUPERPOWER}

Reading faces is a superpower that you can get better at the more you learn about it and the more you practice it. There are also different games you could play with your friends to see who amongst you is better at reading emotions. For example, you could make pictures or cards with faces expressing different emotions (happy, angry, sad, surprised, afraid, disgusted). Then someone can pull a card and try to enact the emotion from the card without using any words-just their faces. Others should guess which emotion the person with the card is trying to portray. As a bonus, you will get to practice your acting skills!

One way to test your emotion-reading skills is the "Reading the Mind in the Eyes Test," which was developed by British scientist Simon-Baron Cohen. In this test, participants rate emotional expressions based only on pictures of the eyes, so without seeing the rest of the face. This is relatively difficult and often feels like guessing, but it turns out that most people are quite 
skilled in doing this task. A nice online version of this test can be found at this link. ${ }^{1}$

\section{CONCLUSION}

Most of us have the superpower of being able to read other people's emotions and we all use the same map-the face-to do it. However, as scientists have shown, we may be using the map a bit differently depending on where we are from, despite using the same brain systems. The cultural differences in our beliefs, behaviors, and display rules will influence the way we both show and read emotions. These cultural differences will even affect which facial clues we choose to focus our attention on when reading emotions. Learning about these differences in the way people read emotions may help us communicate with people from around the world more successfully.

\section{REFERENCES}

1. Morton, J., and Johnson, M. H. 1991. CONSPEC and CONLERN: a two-process theory of infant face recognition. Psychol. Rev. 98(2):164-81. doi:10.1037/0033295X.98.2.164

2. Meltzoff, A. N., and Moore, M. K. 1977. Imitation of facial and manual gestures by human neonates. Science. 198(4312):75-8. doi:10.1126/science.198.4312.75

3. Kanwisher, N., McDermott, J., and Chun, M. M. 1997. The fusiform face area: a module in human extrastriate cortex specialized for face perception. J. Neurosci. 17(11):4302-11.

4. Ishai, A. 2008. Let's face it: it's a cortical network. Neuroimage 40(2):415-9. doi:10.1016/j.neuroimage.2007.10.040

5. Wada, Y., and Yamamoto, T. 2001. Selective impairment of facial recognition due to a haematoma restricted to the right fusiform and lateral occipital region. J. Neurol. Neurosurg. Psychiatry 71(2):254-7. doi:10.1136/jnnp.71.2.254

6. Ekman, P. 1971. Universals and cultural differences in facial expressions of emotion. In: Cole J., editor. Nebraska Symposium on Motivation. (Vol. 19), Lincoln, NE: University of Nebraska Press. p. 207-82.

7. Jack, R. E., Blais, C., Scheepers, C., Schyns, P. G., and Caldara, R. 2009. Cultural confusions show that facial expressions are not universal. Curr. Biol. 19:1543-8. doi:10.1016/j.cub.2009.07.051

8. Yuki, M., Maddux, W. W., and Masuda, T. 2007. Are the windows to the soul the same in the East and West? Cultural differences in using the eyes and mouth as cues to recognize emotions in Japan and the United States. J. Exp. Soc. Psychol. 43(2):303-11. doi:10.1016/j.jesp.2006.02.004

SUBMITTED: 26 October 2016; ACCEPTED: 28 March 2017; PUBLISHED ONLINE: 24 April 2017.

${ }^{1}$ http://socialintelligence.labinthewild.org/mite/ 
EDITED BY: Peter Hagoort, Radboud University Nijmegen, Netherlands

CITATION: Pogosyan M and Engelmann JB (2017) How We Read Emotions from Faces. Front. Young Minds 5:11. doi:10.3389/frym.2017.00011

CONFLICT OF INTEREST STATEMENT: The author declares that the research was conducted in the absence of any commercial or financial relationships that could be construed as a potential conflict of interest.

COPYRIGHT () 2017 Pogosyan and Engelmann. This is an open-access article distributed under the terms of the Creative Commons Attribution License (CC BY). The use, distribution and reproduction in other forums is permitted, provided the original author(s) or licensor are credited and that the original publication in this journal is cited, in accordance with accepted academic practice. No use, distribution or reproduction is permitted which does not comply with these terms.

\section{REVIEWED BY}

\section{JENAPLANSCHOOL DE LANTEERNE, 9-10 YEARS OLD}

$\mathrm{Hi}$, we are the Purple Roses! We are a bilingual group and have one English and one Dutch teacher. We love playing games, dance together, hold class meetings, and do sports. We also like to learn about the world, that is why we enjoy reading things about science!

\section{AUTHORS}

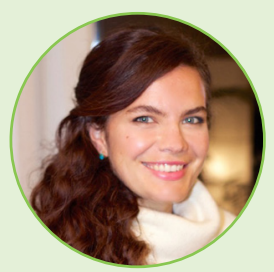

\section{MARIANNA POGOSYAN}

I am interested in the different ways that culture affects people-from the way we think and feel, to the way we interpret the world. I write articles about culture and psychology and help people who have moved to new countries to adapt to their new homes. In my spare time, I enjoy traveling and writing novels.

\section{JAN BENJAMIN ENGELMANN}

My research focuses on how emotions influence our decisions. I am particularly interested in social decision-making, such as when we decide to trust someone, or when others are unfair to us. In order to understand how the brain is involved in decision-making, we combine methods from Behavioral Economics, Psychology and Affective and Computational Neuroscience. *j.b.engelmann@uva.nl 